\title{
A Small Paramagnetic Platinum Cluster in an NaY Zeolite: Characterization and Hydrogen Adsorption and Desorption
}

\author{
X. Liu, ${ }^{\dagger}$ H. Dilger, ${ }^{\dagger}$ R. A. Eichel, ${ }^{\ddagger}$ J. Kunstmann, ${ }^{\S}$ and E. Roduner $*, \dagger$ \\ Institut für Physikalische Chemie, Universität Stuttgart, Pfaffenwaldring 55, D-70569 Stuttgart, Germany, \\ Eduard-Zintl-Institute, Darmstadt University of Technology, Petersenstrasse 20, D-64287 Darmstadt, Germany, \\ and Max Planck Institute for Solid State Research, Heisenbergstrasse 1, D-70569 Stuttgart, Germany
}

Received: October 27, 2005; In Final Form: December 7, 2005

\begin{abstract}
A well-defined cluster containing 12 equivalent platinum atoms was prepared by ion exchange of an $\mathrm{NaY}$ zeolite, followed by hydrogen reduction. It was characterized by electron paramagnetic resonance (EPR) spectroscopy, hyperfine sublevel correlation (HYSCORE), and theoretical calculations. Combing the results of the experiments with density functional calculations, the likely structure of this cluster is icosahedral $\mathrm{Pt}_{13} \mathrm{H}_{m}$, possibly with a low positive charge. The adsorbed H/D on the Pt cluster surface can be exchanged reversibly at room temperature. From H/D desorption experiments, an $\mathrm{H}_{2}$ binding energy of $1.36 \mathrm{eV}$ is derived, in reasonable agreement with the calculated value but clearly larger than that for a (111) Pt single-crystal surface, revealing a finite size effect. While the hydrogen-covered cluster should clearly be regarded as a molecule, it is conceivable that the cluster adopts metallic character upon hydrogen desorption. It is likely that up to $m$ $=30 \mathrm{H}$ atoms bind to this cluster with 12 surface atoms, which has important implications for the determination of the dispersion of small Pt catalyst particles by hydrogen chemisorption. Calculations as well as experiments give evidence of an interesting magnetic behavior with high-spin states playing a prominent role. There are strong indications that a reservoir of EPR silent but structurally similar clusters exists which can partly be converted to EPR visible species by H/D exchange or by gas adsorption.
\end{abstract}

\section{Introduction}

Small metal clusters often show physical and chemical properties different from those of bulk materials, ${ }^{1-7}$ for example, enhanced activity and selectivity in heterogeneous catalysis and high magnetic moments due to uncompensated spins at the cluster surface.

Platinum clusters dispersed in zeolites or porous oxide supports are highly active catalysts for the oxidation of $\mathrm{CO}$ and residual hydrocarbons in automotive exhaust catalysis and for hydrogenation in petrochemical reactions and other commercial applications. Clusters are commonly prepared by aqueous solution ion exchange or impregnation to introduce the platinum ions into the zeolite pores and cages. It is followed by calcination and reduction in hydrogen. ${ }^{9-15}$

The interaction between hydrogen and metal surfaces has been investigated extensively using both experimental and theoretical methods in order to unveil the effects of hydrogen on their reactivity as well as the nature of the bonds. ${ }^{16-26}$ It is generally believed that the adsorbed hydrogen on the metal catalysts surface plays a very important role in catalytic reactions since hydrogen chemisorption modifies the electronic properties of the metal, which results in a change of the catalytic properties. The adsorbed hydrogen ties up the conduction electrons of the surface atoms in the bonds to the adsorbate, so that the surface metal atoms show electronic and magnetic properties different from those of the core atoms. ${ }^{26,27}$

* To whom correspondence should be addressed. Fax (+49) 711-6854495. E-mail: e.roduner@ipc.uni-stuttgart.de.

$\uparrow$ Universität Stuttgart.

$\doteqdot$ Darmstadt University of Technology.

$\S$ Max Planck Institute for Solid State Research.
Hydrogen chemisorption is often used to determine the fraction of surface platinum atoms in platinum catalysts. The stoichiometry is then normally assumed to be one $\mathrm{H}$ atom per surface Pt atom. However, it should be taken into account that it can be affected by various effects such as spillover of hydrogen atoms from the metal to the surface of the support, the formation of hydrides or solid solutions between hydrogen and the metal catalyst, the presence of contaminants, and adsorption geometries different from bonding atop of each atom.

Small noble metal clusters present novel magnetic properties, which are absent in the bulk. ${ }^{28-33} \mathrm{Pt}$ nanoparticles protected by poly- $N$-vinyl-2-pyrrolidine (PVP) with a diameter below 3 nm exhibited superparamagnetic behavior and strongly enhanced magnetization compared to the paramagnetic moments in the bulk state. ${ }^{34}$ In supported metal catalysts, the clusters are normally assumed to present a broad size and shape distribution. In contrast, for free clusters, special numbers (so-called "magic numbers") of atoms occur much more frequently than others since elements exhibiting electron deficient metallic bonding prefer a maximum coordination resulting in various close-packed polyhedral structures. ${ }^{35} \mathrm{In}$ the case of platinum, $\mathrm{Pt}_{13}$ is one of the smallest magic clusters in which 12 equivalent Pt nuclei surround a central Pt atom.

It is well-known that the size, shape, and morphology of $\mathrm{Pt}$ clusters affect not only the activity but also the selectivity of catalysts. A clear trend of increasing catalytic activities with decreasing Pt cluster size has been established since the smaller the cluster the larger the fraction of available surface atoms for catalytic reactions. ${ }^{36-38}$ To prepare and characterize small metallic clusters with controlled homogeneous size has therefore been a desired aim in nanocatalysis research. Thus, it is of considerable interest to synthesize well-defined clusters for 
understanding catalytic properties and elementary steps of catalytic processes as well as possibly realizing catalysis on single well-defined clusters.

Electron paramagnetic resonance (EPR) is a useful method to characterize small paramagnetic clusters and ions in zeolites without destroying their structures. ${ }^{39-42}$ Information about cluster size, structure, charge, and local environment can be obtained. Besides those, exclusive paramagnetism of EPR active metal clusters can be separated from other magnetic behavior based on the study of temperature-dependent EPR spectra. Pulse EPR can provide temperature-dependent spin lattice relaxation time $T_{1}$ of small metal clusters, which provides direct evidence to judge the metallic or nonmetallic property of small metal clusters.

Recently, a highly symmetric paramagnetic cluster with 12 equivalent Pt atoms was prepared in a KL zeolite and characterized by continuous wave and pulse EPR. ${ }^{43}$ Electron nuclear double resonance (ENDOR) and hyperfine sublevel correlation (HYSCORE) experiments revealed the proton hyperfine couplings of the surface adsorbed hydrogen. The observed species was attributed to a $\mathrm{Pt}_{13} \mathrm{H}_{m}{ }^{n+}(n=1$ or 3$)$ cluster with an icosahedral structure. As an extension of this work, we aim here at a characterization from both an experimental and theoretical point of view to analyze the structure in a more symmetric zeolite and to investigate the reversible exchange and thermal desorption dynamics of $\mathrm{H} / \mathrm{D}$ on this well-defined cluster.

\section{Experimental and Quantum Chemical Procedures}

2.1. Sample Preparation. An $\mathrm{NaY}$ zeolite was obtained from CU Chemie Uetikon AG in Switzerland. It was calcined in air at $773 \mathrm{~K}$ for $14 \mathrm{~h}$ after heating it at a rate of $1 \mathrm{~K} \cdot \mathrm{min}^{-1}$ to burn off any organic impurities. $\mathrm{Pt} / \mathrm{NaY}$ samples were prepared by ion exchange with $3 \mathrm{mM}$ aqueous $\left[\mathrm{Pt}\left(\mathrm{NH}_{3}\right)_{4}\right] \mathrm{Cl}_{2}$ (Aldrich) solution added dropwise to a flask containing $1 \mathrm{~g}$ of $\mathrm{NaY}$ zeolite and $200 \mathrm{~mL}$ of water, followed by stirring at $343 \mathrm{~K}$ for about $48 \mathrm{~h}$. It was verified by chemical analysis that this procedure leads to a Pt loading of ca. $6 \mathrm{wt} \%$. The exchanged zeolite was filtered, washed with deionized water to remove $\mathrm{Cl}^{-}$ions, and dried at room temperature in a vacuum overnight. The subsequent calcination was carried out in flowing $\mathrm{O}_{2}$ $\left(100 \mathrm{~mL} \cdot \mathrm{min}^{-1} \cdot \mathrm{g}^{-1}\right)$ using a heating rate of $0.5 \mathrm{~K} \cdot \mathrm{min}^{-1}$ from room temperature to $573 \mathrm{~K}$ and holding $573 \mathrm{~K}$ for $5 \mathrm{~h}$. After the sample had cooled to room temperature, $\mathrm{N}_{2}$ was applied to purge the residual $\mathrm{O}_{2}$ in the reactor. The reduction was performed in flowing hydrogen $\left(100 \mathrm{~mL} \cdot \mathrm{min}^{-1} \cdot \mathrm{g}^{-1}\right)$ with a heating rate of $6 \mathrm{~K} \cdot \mathrm{min}^{-1}$ from room temperature to $473 \mathrm{~K}$ and keeping it at $473 \mathrm{~K}$ for $1 \mathrm{~h}$. After the sample had cooled to room temperature in hydrogen atmosphere, it was transferred into EPR tubes in a glovebox under $\mathrm{N}_{2}$ and then evacuated.

For hydrogen isotope exchange, deuterium gas was filled into an evacuated EPR quartz tube (outer diameter about $4 \mathrm{~mm}$ ) containing about $200 \mathrm{mg} \mathrm{H}$-reduced $\mathrm{Pt} / \mathrm{NaY}$. The gas was kept for $30 \mathrm{~min}$ at a $\mathrm{D}_{2}$ partial pressure of $500 \mathrm{mbar}$ at room temperature. For hydrogen desorption experiments, the EPR tube containing $200 \mathrm{mg}$ of $\mathrm{Pt} / \mathrm{NaY}$ powder was connected to a turbomolecular pump, evacuated, and heated in a small oven at 393 , 408, or $418 \mathrm{~K}$ for different time intervals. Thereafter, the sample was sealed via a stopcock for use in the EPR spectrometer.

2.2. Electron Paramagnetic Resonance. $\mathrm{cw} X$-band EPR spectra were recorded on a Bruker EMX spectrometer with a microwave frequency of about $9.466 \mathrm{GHz}$ from 4 to $295 \mathrm{~K}$. To avoid saturation of signals, an optimized power of $1 \mathrm{~mW}$ was chosen for the experiments. All recording parameters were kept fixed for measurements of the spectra as a function of temperature. The pulse X-band EPR measurements were performed on a Bruker ElexSys E580 spectrometer with a microwave frequency of about $9.6 \mathrm{GHz}$. All HYSCORE and ENDOR spectra were recorded with the magnetic field set at the maximum EPR absorption.

The spin concentration of a sample was calibrated using a standard sample (ultramarine blue diluted by $\mathrm{KCl}$ ).

EPR spectral simulation was treated in the same way as described in the previous work. ${ }^{43}$ High-field conditions were assumed so that the effects of the nuclear field on the alignment of the electron spin are negligible, and the electron problem can be treated independently. A coaxial system of hyperfine and $g$ tensors was applied for the simulation. Since each nucleus is treated independently, this allows for more flexibility with near-equivalent nuclei. However, it has the disadvantage that the higher-order shifts present in multiple equivalent nuclei are not accounted for, which leads to anisotropic line shapes. For our present simulation, this may be responsible in part for the incomplete match of simulated and experimental spectra. For the EPR spectral simulation of the Pt cluster, all possible Pt isotope distributions weighted with the corresponding statistical probabilities were taken into account. ${ }^{43}$

2.3. Density Functional Calculations. DFT calculations were carried out using the VASP ab initio package, version 4.4.6. ${ }^{44}$ The code uses plane-wave basis sets and can model solid materials, surfaces, or clusters. During all simulations, we used the projector augmented wave (PAW) ${ }^{45}$ approach, and electronic correlations were treated with the Perdew-Wang 91 form of the generalized gradient approximation (GGA) ${ }^{46}$

To correctly describe the ground state and the magnetic properties of the clusters, the collinear spin-polarized version of DFT was used. For charged systems, a multipole correction scheme was applied to correct the leading errors in the total energy that are induced by the finite size of the supercell. ${ }^{47}$ To optimize the structure of the cluster effectively, we employed a conjugate gradient algorithm and allowed all atomic coordinates to relax.

For the expansion of the electronic wave function in a planewave basis set, a cutoff energy of $250 \mathrm{eV}$ was used. All clusters were placed in a cubic supercell with a lattice constant of 15 $\AA$. Here, the distance between two adjacent $\mathrm{Pt}$ atoms in neighboring supercells is around $10 \AA$ which was sufficient to reduce the error in the total energy due to the periodic boundary conditions to less than $1 \mathrm{meV}$ per atom. A single k-point placed at the $\gamma$ point of the reciprocal unit cell and a Gaussian smearing of $0.05 \mathrm{eV}$ were used to carry out the k-space integration; the error induced by these parameters was checked to be less than $2 \mathrm{meV}$ per atom. During geometry optimization, all interatomic forces were reduced to below $0.04 \mathrm{eV} / \AA$; in very rare cases, forces on individual atoms reached $0.08 \mathrm{eV} / \AA$.

The hydrogen adsorption energies per $\mathrm{H}_{2}$ molecule were calculated as the difference between the energy of Pt clusters covered with $n$ hydrogen atoms and the sum of the energies of the bare Pt cluster and the gas-phase hydrogen molecule. They are given by

$$
E_{\text {ads }}\left(\mathrm{H}_{2}\right)=\frac{2}{n}\left[E_{\mathrm{Pt}+n \mathrm{H}}-\left(E_{\mathrm{Pt}}+\frac{n}{2} E_{\mathrm{H}_{2}}\right)\right]
$$

where $E_{\mathrm{Pt}+n \mathrm{H}}, E_{\mathrm{Pt}}$, and $E_{\mathrm{H}_{2}}$ represent the total energies of the hydrogen-reduced $\mathrm{Pt}_{13}$ cluster, the bare $\mathrm{Pt}_{13}$ cluster, and a gasphase hydrogen molecule, respectively. In the following, the desorption energy $E_{\mathrm{des}}=-E_{\text {ads }}$ will be quoted, and it should 


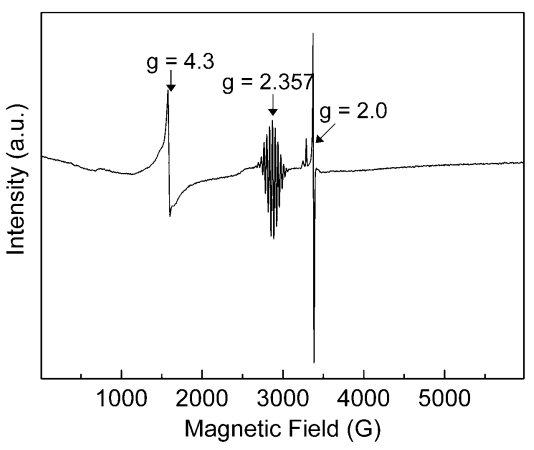

Figure 1. X-band EPR spectrum of $6 \% \mathrm{Pt} / \mathrm{NaY}$ recorded at $20 \mathrm{~K}$, showing the Pt cluster signal $(g=2.357)$ as well as the well-known iron signal $(g=4.3)$ from impurities in the zeolite and a third signal $(g=2.00)$ that is ascribed to the zeolite (see text).

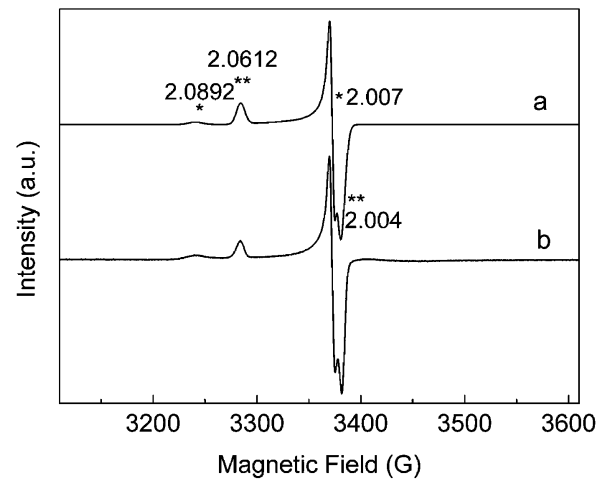

Figure 2. Simulated (a) and experimental EPR spectrum (b) for the signal with $g \approx 2.00$ in an enlarged range. The signal labeled $*$ is from one species with $g_{\perp}=2.0070$ and $g_{\|}=2.0892$, and the signal labeled with $* *$ is from another species with $g_{\perp}=2.0040$ and $g_{\|}=$ 2.0612 .

be noted that the reference state is always molecular and not atomic hydrogen.

\section{Results}

3.1. EPR Investigations. Figure 1 shows an X-band EPR spectrum of $6 \% \mathrm{Pt} / \mathrm{NaY}$ reduced in deuterium gas that was measured at $20 \mathrm{~K}$. Besides the typical iron peak $(g=4.3)^{48}$ from small amounts of iron impurities in zeolite as reported in previous work, there are two signals with $g \approx 2.00$ and $g=$ 2.357, which are shown enlarged in Figure 2 and Figure 3.

The signal with $g \approx 2.00$ is a superposition of two axial $g$ species which show different temperature dependences. The corresponding simulations and the parameters are displayed in Figure 2. The signal of the species with $g_{\perp}=2.007$ almost disappears above $80 \mathrm{~K}$. However, the species with $g_{\perp}=2.004$ still survives even at room temperature. No nuclear hyperfine couplings due to $\mathrm{Pt}$ or $\mathrm{H}$ were detected in the Mims ENDOR experiments at $g=2.007$. Furthermore, the signals are present also in the absence of Pt after an otherwise identical treatment. The HYSCORE spectrum recorded at $3341 \mathrm{G}$ and $10 \mathrm{~K}$ is shown in Figure 4. The signal near 4.0 MHz is compatible with the Zeeman frequency of residual sodium, $v_{\mathrm{Na}}=3.77 \mathrm{MHz}$, or with $\mathrm{Al}$ at $v_{\mathrm{Al}}=3.71 \mathrm{MHz}$. It reveals a small isotropic hyperfine coupling of $2.6 \mathrm{MHz}$ which translates into a fractional spin population of $2.9 \times 10^{-3}$ for $\mathrm{Na}$ or $6.7 \times 10^{-4}$ for $\mathrm{Al}$. On the basis of the dipolar shift of $\Delta v_{\mathrm{s}} \approx 0.32 \mathrm{MHz}$ of the ridges from the nominal nuclear Zeeman frequency, we obtain $T \approx 2.06$ $\left.\operatorname{MHz}(T=4]_{3}\left(2 v_{\mathrm{N}} \Delta v_{\mathrm{s}}\right)^{1 / 2}=\mu_{0} g_{\mathrm{N}} g_{\mathrm{e}} \beta_{\mathrm{N}} \beta_{\mathrm{e}} / 4 \pi h r^{3}\right)^{43}$ from which we derive a point dipole distance of the nucleus from the unpaired electron of $2.2 \AA{ }^{50} \mathrm{Al}-\mathrm{O}$ bonds can in exceptional

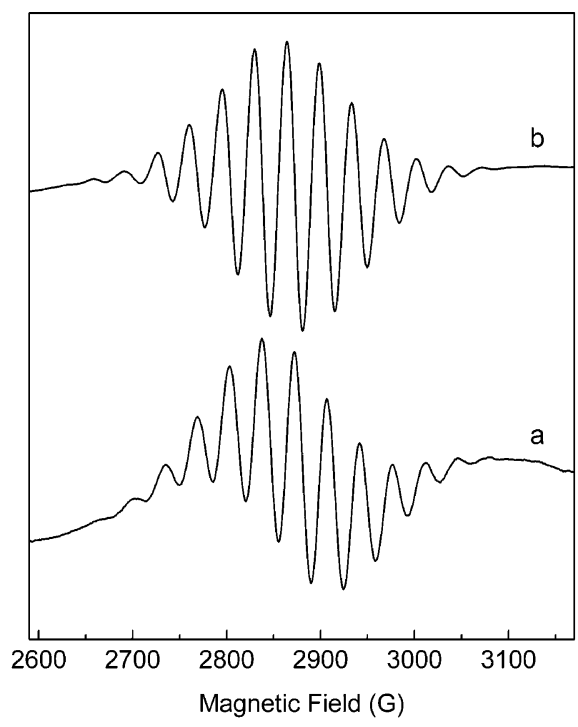

Figure 3. X-band EPR spectra of $6 \% \mathrm{Pt} / \mathrm{NaY}$ recorded at $20 \mathrm{~K}$ : (a) $\mathrm{H}_{2}$-reduced species and (b) $\mathrm{D}_{2}$-reduced species.

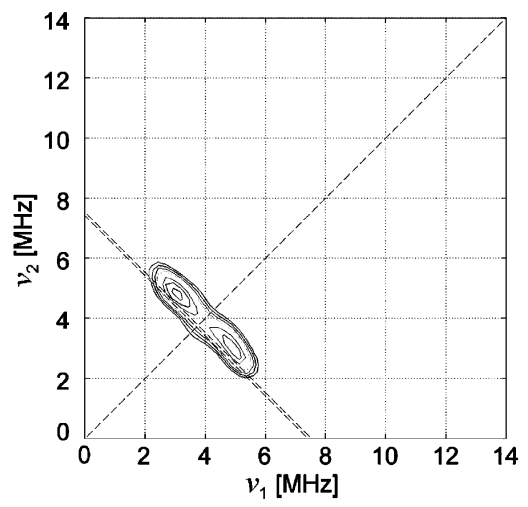

Figure 4. HYSCORE spectrum of the $\mathrm{H}_{2}$-reduced sample recorded at $3341 \mathrm{G}$ and $10 \mathrm{~K}$. The two broken lines parallel to the antidiagonal give the expected unshifted signal positions $\left(\Delta v_{\mathrm{s}}=0\right)$ for sodium and aluminum.

cases be very long ${ }^{51}$ so that it is difficult to decide whether the observed hyperfine coupling has to be assigned to $\mathrm{Al}$ or to $\mathrm{Na}$, but it should be clear that the two $g \approx 2.00$ signals are not related to Pt. They are thus not in the focus of the present work.

The dominant signal with $g=2.357$ is a multiplet representing a Pt cluster. The possibility that the hyperfine structure originates from the $\mathrm{Na}$ nuclei is excluded because Pt loaded in $\mathrm{KL}, \mathrm{LiL}$, and $\mathrm{NaX}$ zeolites gives similar EPR spectra, while in the absence of $\mathrm{Pt}$ there is no such multiplet. ${ }^{43}$ Furthermore, isotopically enriched $\mathrm{Pt}$ samples proved unambiguously that the splitting is due to Pt. For different zeolites, $g$ exhibits a relatively small shift because the EPR signal depends slightly on the zeolite structure as well as on the $\mathrm{Si} / \mathrm{Al}$ ratio. Compared with $\mathrm{Pt} / \mathrm{KL},{ }^{43}$ although the main features are the same, the $g$ value of the multiplet is slightly smaller and the spectra are more symmetrical in $\mathrm{Pt} / \mathrm{NaY}$ (see Table 1). It can be seen from Figure 3 that a sample reduced with $\mathrm{D}_{2}$ gas instead of $\mathrm{H}_{2}$ gives rise to slightly narrower lines. This means that the proton hyperfine coupling is unresolved but affects the line widths. The isotropic Pt hyperfine coupling constant is about $68.8 \mathrm{G}$. The $g$ value is much larger than $g_{\mathrm{e}}$, which for simple transition metal centers indicates that the unpaired electrons come from a more than half-filled $\mathrm{d}$ shell. ${ }^{49}$ As in the previous work with $\mathrm{Pt} / \mathrm{KL}$ and verified below for $\mathrm{Pt} / \mathrm{NaY}$, this observed highly symmetrical EPR multiplet is from 12 equivalent Pt nuclei. 
TABLE 1: EPR Parameters from Simulation of 12 Equivalent Pt Nuclei to Experimental Spectra

\begin{tabular}{|c|c|c|c|c|c|c|c|c|}
\hline \multirow[b]{2}{*}{ species } & \multicolumn{4}{|c|}{$g$} & \multicolumn{4}{|c|}{$A_{\mathrm{Pt}}(\mathrm{G})$} \\
\hline & $g_{\perp}$ & $g_{\|}$ & $g_{\|}-g_{\perp}$ & $g_{\text {iso }}$ & $A_{\perp}$ & $A_{\|}$ & $A_{\|}-A_{\perp}$ & $A_{\text {iso }}$ \\
\hline $\mathrm{H}_{2}$-reduced $\mathrm{Pt} / \mathrm{KL}^{a}$ & 2.3540 & 2.4260 & 0.0720 & 2.3780 & 67.9 & 55.9 & -12.0 & 63.9 \\
\hline $\mathrm{D}_{2}$-reduced $\mathrm{Pt} / \mathrm{KL}^{a}$ & 2.3600 & 2.4450 & 0.0850 & 2.3883 & 67.6 & 55.6 & -12.0 & 63.6 \\
\hline $\mathrm{H}_{2}$-reduced $\mathrm{Pt} / \mathrm{NaY}^{b}$ & 2.3460 & 2.4150 & 0.0690 & 2.3690 & 69.2 & 68.4 & -0.80 & 68.9 \\
\hline $\mathrm{D}_{2}$-reduced $\mathrm{Pt} / \mathrm{NaY}{ }^{b}$ & 2.3558 & 2.3594 & 0.0036 & 2.3570 & 71.2 & 64.0 & -7.2 & 68.8 \\
\hline $\begin{array}{l}{\text { after } \mathrm{D}_{2} \text { desorption }}^{b} \\
\text { at } 343 \mathrm{~K}(\mathrm{Pt} / \mathrm{NaY})\end{array}$ & 2.3550 & 2.3580 & 0.0030 & 2.3560 & 66.5 & 73.4 & +6.9 & 68.8 \\
\hline $\begin{array}{l}\text { after } \mathrm{D}_{2} \text { desorption } \\
\text { at } 393 \mathrm{~K}(\mathrm{Pt} / \mathrm{NaY})\end{array}$ & 2.3520 & 2.3580 & 0.0060 & 2.3540 & 67.7 & 71.0 & +3.3 & 68.8 \\
\hline
\end{tabular}

${ }^{a}$ Reference $43 .{ }^{b}$ This work.

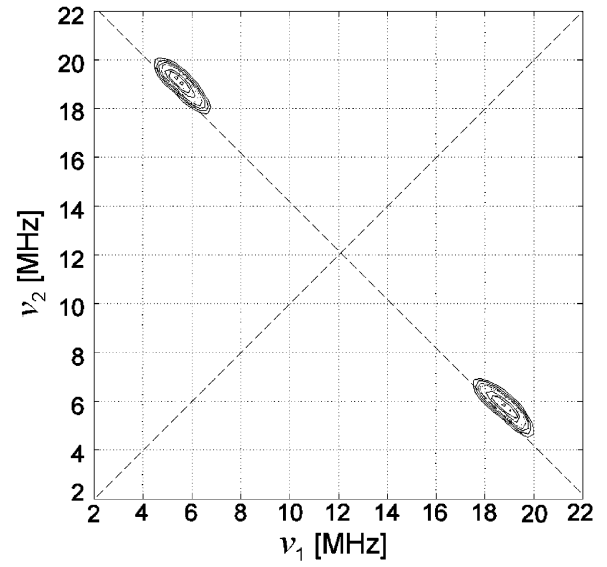

Figure 5. HYSCORE spectrum of the $\mathrm{H}_{2}$-reduced sample recorded at $2840 \mathrm{G}$ and $10 \mathrm{~K}$. The two patterns along the antidiagonal represent strongly coupled protons.

It is interesting to find that the adsorbed $\mathrm{H}_{2}$ on the platinum cluster surface can be exchanged by $\mathrm{D}_{2}$ at room temperature, when deuterium gas is filled into the EPR tube and kept in contact with the sample at a pressure of 500 bar for $30 \mathrm{~min}$ and vice versa (see Figure 3 ). This is a fully reversible process. Exposure of the $\mathrm{H}_{2}$-reduced sample to $\mathrm{D}_{2}$ results in considerably narrower lines, but the main feature of the spectra remains the same. However, the deuterium-reduced or exchanged samples always give a stronger EPR signal by a factor of about 2.8 (based on the value of the double integral) than hydrogen-reduced or exchanged samples.

Pulse EPR methods are powerful for providing the hyperfine couplings from the environment. The interaction of $\mathrm{H}$ or $\mathrm{D}$ with the Pt species is reflected in the ENDOR and HYSCORE spectra. The Mims H-ENDOR spectrum (not shown) recorded at a magnetic field of $287.3 \mathrm{mT}$ and a microwave frequency of about $9.6 \mathrm{GHz}$ revealed a center frequency $\nu_{\mathrm{H}}=12.4 \mathrm{MHz}$ that corresponds to the proton Zeeman frequency, and the corresponding signal indicates the presence of weakly coupled protons in the environment. On the basis of the splittings of $A_{\|}{ }^{\mathrm{H}}=15.3 \pm 0.5 \mathrm{MHz}$ and $A_{\perp}{ }^{\mathrm{H}}=10.5 \pm 0.5 \mathrm{MHz}$, the corresponding isotropic proton hyperfine coupling constant is $A_{\text {iso }}=\left(2 A_{\perp}+A_{\| \mid}\right) / 3=12.1 \mathrm{MHz}$. Thus, the proton hyperfine anisotropy is considerably lower than that observed previously in a KL zeolite, where $A_{\|}{ }^{\mathrm{H}}=18.5 \mathrm{MHz}$ and $A_{\perp}{ }^{\mathrm{H}}=9.0 \mathrm{MHz}$ were reported. ${ }^{43}$

The HYSCORE spectrum recorded at $g_{\perp}$ is shown in Figure 5. The two ridges along the antidiagonal represent the hyperfine coupled protons and are separated by about $A_{\text {iso }}{ }^{\mathrm{H}}=13.2 \mathrm{MHz}$, in good agreement with the results obtained from the ENDOR spectrum. The maximum frequency shift $\left(\Delta \nu_{\mathrm{s}} \approx 0.16 \mathrm{MHz}\right)$ of the ridges from the antidiagonal corresponds to a dipolar contribution to the hyperfine coupling of $T \approx 2.63 \mathrm{MHz} .{ }^{50}$ This
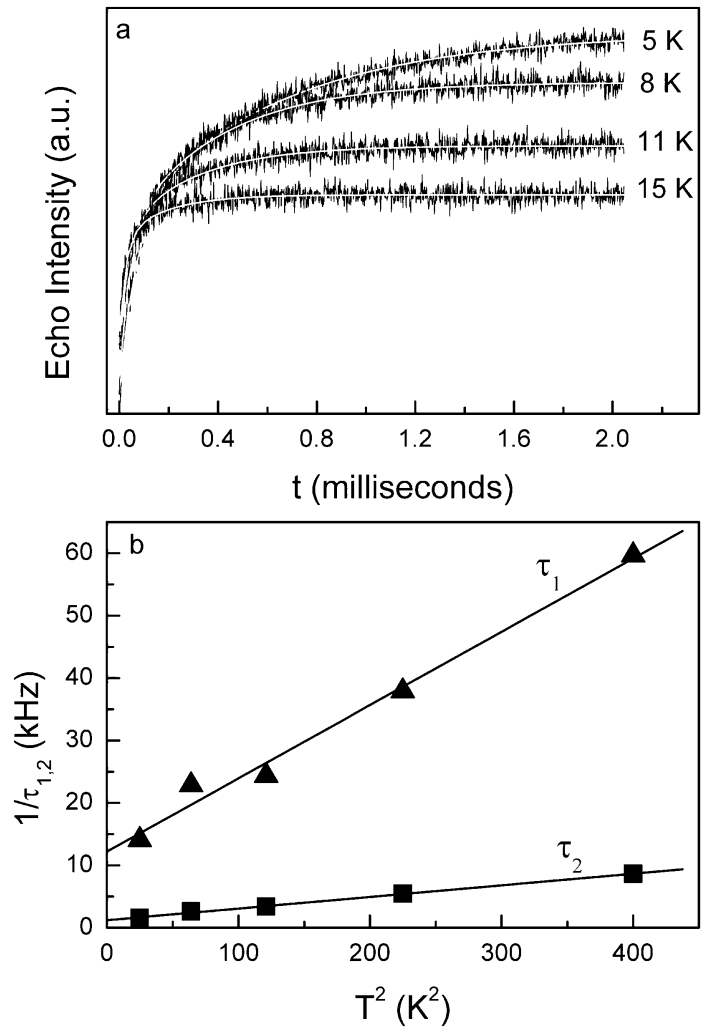

Figure 6. (a) Saturation-recovery curves recorded at $2840 \mathrm{G}$ for the $\mathrm{D}_{2}$-reduced sample and the corresponding fit by a double-exponential function for temperatures of $5,8,11$, and $15 \mathrm{~K}$, respectively, and (b) plot of longitudinal relaxation rates as a function of temperature squared.

indicates that the broad ENDOR lines are caused by dipolar interactions rather than by a distribution of isotropic hyperfine couplings.

The measured proton hyperfine interaction (Figure 5) is expected to lead to a multiplet with a splitting of about 13.2 $\mathrm{MHz}$. This is not resolved in the EPR spectra but contributes to the line widths. The different line widths for the sample reduced with $\mathrm{H}_{2}$ and $\mathrm{D}_{2}$ (or reduced with $\mathrm{H}_{2}$ then exchanged with $\mathrm{D}_{2}$ ) are due to the fact that the magnetic moment of the deuteron is a factor 6.5 smaller than that of the proton and thus the hyperfine splitting of $\mathrm{H}$ is 6.5 times larger than that for $\mathrm{D}$.

Pulsed EPR using the spin-echo method is a direct technique for the determination of the electron spin lattice relaxation. The $T_{1}$ relaxation experiments were performed by monitoring the saturation recovery of the two-pulse echo at the field position corresponding to the maximum absorption. Figure 6a shows the typical echo-detected saturation recovery curves of the Pt cluster at different temperatures. The relaxation rate depends strongly on temperature. Above $30 \mathrm{~K}$, it becomes too fast to be detectable, but it is nevertheless too low to affect the line width 


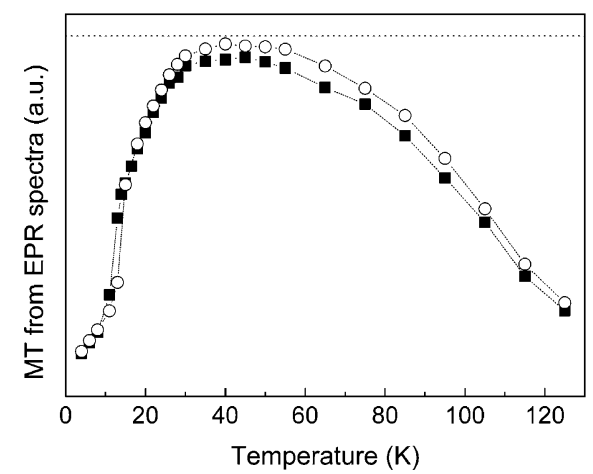

Figure 7. Product of magnetization times temperature vs temperature plot obtained with $\mathrm{D}_{2}$-reduced $6 \% \mathrm{Pt} / \mathrm{NaY}$ from doubly integrated $\mathrm{EPR}$ spectra of the $\mathrm{Pt}_{13}$ cluster signal upon heating after field cooling (filled squares) and zero-field cooling (open circles). The broken line indicates the expectation for Curie behavior. The discontinuity at $17 \mathrm{~K}$ comes out much more clearly when the magnetization is plotted directly.

by more than a few tens of milligauss. It was necessary to use a double-exponential function to fit the curves. The two components have close to the same weight. The corresponding spin-lattice relaxation rates $1 / \tau_{1}$ and $1 / \tau_{2}$ both have a $T^{2}$ temperature dependence (see Figure 6b).

The double integral of the EPR spectrum is proportional to the magnetization. Figure 7 displays the product of magnetization and temperature as a function of temperature for both field cooling and zero-field cooling. For Curie-type paramagnetism, a horizontal line is expected. The curve in Figure 7 deviates from such behavior in that it shows quite a sudden jump around $17 \mathrm{~K}$ and a significant decrease above $\approx 60 \mathrm{~K}$. The discontinuity at $17 \mathrm{~K}$ is perhaps the most puzzling finding of the present work. Any explanation of its origin has to take into account the following findings: (i) Except for its amplitude, the cluster EPR spectrum is identical below and above $17 \mathrm{~K}$. This rules out any significant transformation of the cluster identity. A transient nutation experiment performed below $(10 \mathrm{~K})$ and above the jump temperature $(25 \mathrm{~K})$ was dominated by a broad background signal and was thus not conclusive. This background is likely due to the remaining (high-spin) Pt. (ii) The discontinuity appears at the same temperature for a $1 \% \mathrm{Pt}$ loading as for a $6 \%$ loading, thus it is not related to any magnetic interaction between the clusters which are well dispersed anyway (in the average, a $6 \%$ loading corresponds to one $\mathrm{Pt}_{13}$ cluster per 25 supercages of $\mathrm{NaY}$ ). (iii) The discontinuity at $17 \mathrm{~K}$ was also observed for the $g \approx 2$ signal, although with a different relative change in amplitude (about 2), which would point to either an experimental artifact or a phase transition of the zeolite host structure. No discontinuity was observed with other samples under any conditions. (iv) The discontinuity disappeared and the magnetization decreased continuously with increasing temperature for both the Pt cluster signal and the $g \approx 2$ signal when the sample tube was filled with either $\mathrm{He}, \mathrm{Ar}$, or $\mathrm{N}_{2}$ gas at a pressure of 1 bar. This would normally be taken as evidence for insufficient temperature equilibration at the lower temperature. However, the presence of the discontinuity was not influenced by any equilibration time at low temperature nor on whether the data points were taken upon cooling or upon heating.

Figure 8 shows the EPR spectra of the deuterium-reduced cluster recorded at $20 \mathrm{~K}$ after evacuation and heating for different time intervals at $393 \mathrm{~K}$ and finally after reexposure to $\mathrm{D}_{2}$ gas at a pressure of $500 \mathrm{mbar}$ for $60 \mathrm{~min}$. The intensity of the EPR spectrum at $393 \mathrm{~K}$ decreases continuously with desorption time. However, reexposure to $\mathrm{D}_{2}$ gas recovers the

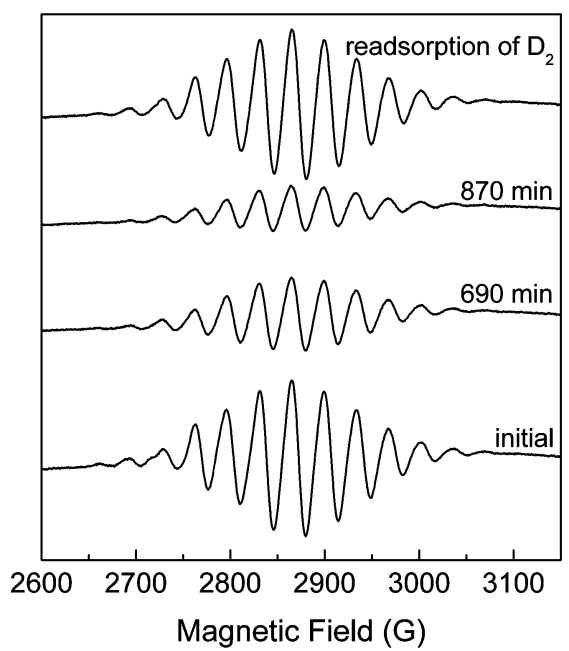

Figure 8. EPR spectra of $6 \% \mathrm{Pt} / \mathrm{NaY}$ recorded at $20 \mathrm{~K}$ after deuterium desorption at $393 \mathrm{~K}$ for different time intervals and after readsorption of $\mathrm{D}_{2}$. Note that upon desorption the spectrum changes only its amplitude but not its splitting pattern.
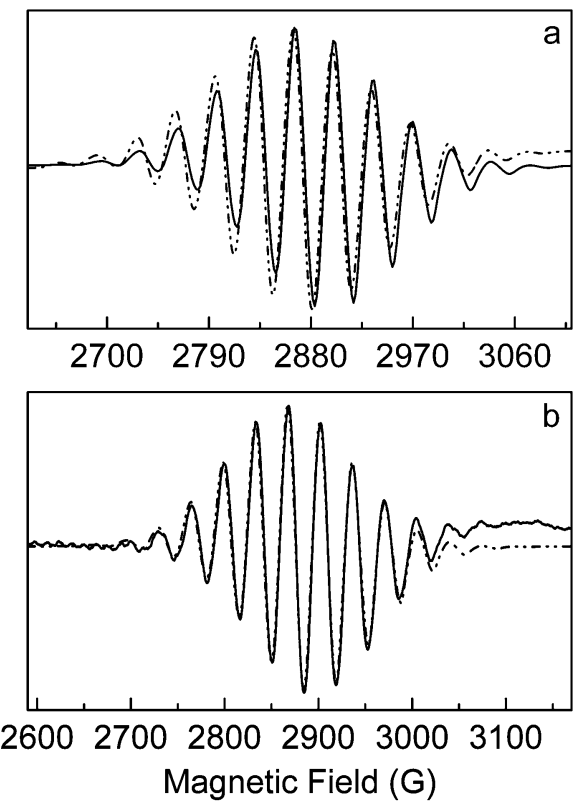

Figure 9. (a) EPR spectrum of the initial sample (line) recorded at 20 $\mathrm{K}$ and the EPR spectrum (after renormalization) of the sample after $\mathrm{D}_{2}$ desorption at $343 \mathrm{~K}$ for $60 \mathrm{~min}$ (dash-dot), and (b) EPR spectrum of the sample after $\mathrm{D}_{2}$ desorption at $393 \mathrm{~K}$ for $60 \mathrm{~min}$ (line) recorded at $20 \mathrm{~K}$ and the corresponding simulation (dash-dot) based on the parameters listed in Table 1 for 12 equivalent Pt nuclei, taking into account the statistical distribution of spin- $-1 / 2 \mathrm{Pt}$ in natural abundance Pt.

EPR cluster signal to almost its initial amplitude, which demonstrates that the cluster is mostly still intact.

Spectral simulation of the $\mathrm{H}_{2}$ - and $\mathrm{D}_{2}$-reduced samples was done based on coaxial $g$ and $A$ tensors as well as assuming a common intrinsic line width and an equal number of $\mathrm{H}$ and $\mathrm{D}$ couplings. The previous work suggests that the number of adsorbed hydrogen nuclei exceeds 8 . When the number of hydrogen nuclei is larger than 8 , the line width is no longer very sensitive to the number of nuclei. ${ }^{43}$ Figure $9 \mathrm{~b}$ shows the EPR spectrum of the sample after $\mathrm{D}_{2}$ desorption at $393 \mathrm{~K}$ for $60 \mathrm{~min}$ recorded at $20 \mathrm{~K}$. The simulation of this spectrum demonstrates that 12 equivalent $\mathrm{Pt}$ nuclei provide a perfect fit to the intensity distribution of the multiplet. A different number of Pt nuclei is clearly incompatible with experiment (not shown). 

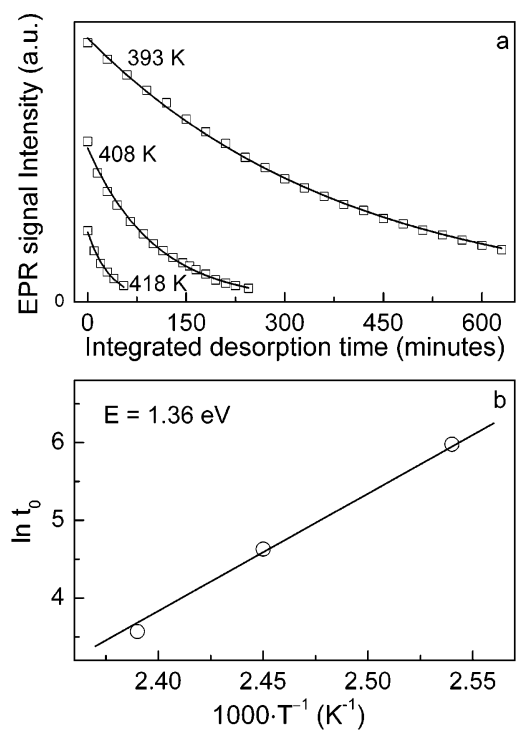

Figure 10. (a) EPR signal intensity vs desorption time at different temperatures and (b) Arrhenius plot of relative rate constants for $\mathrm{D}_{2}$ desorption.

The simulations require an intrinsic (single-crystal) line width of $5 \mathrm{G}$.

There are slight but reproducible differences between the EPR spectra of the initial sample and after $\mathrm{D}_{2}$ desorption at $343 \mathrm{~K}$ for $60 \mathrm{~min}$, as can be seen from Figure 9a and in the corresponding simulation parameters in Table 1. After $\mathrm{D}_{2}$ desorption, besides a slight shift of the $g$ value, there is an obvious but small anisotropy change of the hyperfine coupling tensor. It is revealed by comparison of the left-right asymmetry of the line intensities. Before $\mathrm{D}_{2}$ desorption, $A_{\perp}>A_{\|}$, after $\mathrm{D}_{2}$ desorption, $A_{\perp}<A_{\|}$, while the isotropic Pt nuclear hyperfine coupling keeps constant.

The detailed decay curves as a function of integral desorption time by heating at 393,408 , and $418 \mathrm{~K}$ are displayed in Figure 10a. The higher the desorption temperature, the faster the decrease of intensity. On the basis of the desorption rates in Figure 10a, the hydrogen desorption energy from the Pt cluster is calculated from the slope of the Arrhenius plot as shown in Figure 10b.

3.2. Density Functional Calculations. To test the supplied PAW potentials for $\mathrm{Pt}$ and $\mathrm{H}$ as well as the set of numerical parameters, different atomic and bulk properties were calculated. For bulk (face centered cubic, fcc) platinum, we found a $\mathrm{Pt}-\mathrm{Pt}$ bond length of about $2.82 \AA$ and a bulk modulus of $247 \mathrm{GPa}$, and for atomic platinum, we found an ionization potential of $9.54 \mathrm{eV}$, which compare quite satisfactorily with the experimental values of $2.77 \AA$, $278 \mathrm{GPa}$, and $8.96 \mathrm{eV}$, respectively. For molecular hydrogen, the calculated bond length was 0.75 $\AA$ (experiment, 0.74) and the ionization potential was $15.10 \mathrm{eV}$ (experiment, $15.43 \mathrm{eV}$ ). All of these differences are within the known range of errors of DFT plane-wave calculations. Therefore, the method and the set of numerical parameters are judged to be well suited for our calculations.

The highly symmetrical EPR spectra which are represented by 12 equivalent $\mathrm{Pt}$ nuclei in the simulation suggest an icosahedral structure of the hydrogen-reduced Pt clusters. As in previous work, ${ }^{43}$ it is assumed here that a 13 th atom is located in the center but not resolved in the EPR spectra. The fact that the spectra do depend to some extent on the zeolite structure (see Table 1) demonstrates that there is some interaction between the cluster and the zeolite frame. This is plausible since the size of the $\mathrm{Pt}_{13}$ cluster amounts to about three atomic diameters
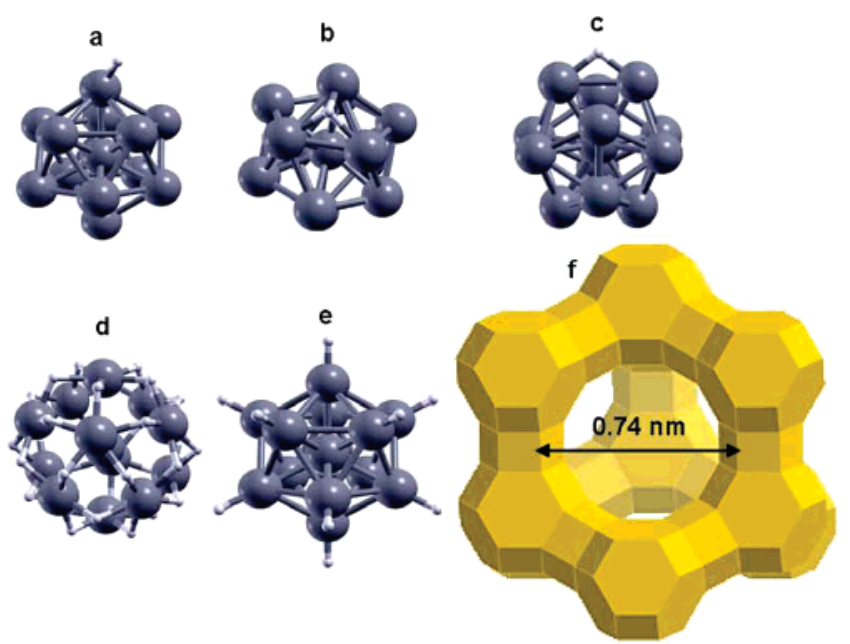

Figure 11. Optimized $\mathrm{Pt}_{13} \mathrm{H}_{1}{ }^{+1}$ clusters (see Table 2): (a) hydrogen atom bound at the top, (b) in the hole, and (c) at the bridge site; (d) Optimized clusters $\mathrm{Pt}_{13} \mathrm{H}_{30}{ }^{+1}$ (bridge site), (e) $\mathrm{Pt}_{13} \mathrm{H}_{12}{ }^{+1}$ (top), and (f) the structure of an $\mathrm{NaY}$ zeolite on scale with the clusters and 12-ring window of the supercage indicated.

(three $\mathrm{Pt}-\mathrm{Pt}$ bond lengths), ca. $8 \AA$, which is slightly more than the open diameter of the 12-ring window of the supercage (Figure 11f). However, the supercages themselves have a diameter of ca. $13 \AA$, which is more than enough to also accommodate the hydrogen-reduced clusters. Unfortunately, it is not a real option to include the zeolite framework in highlevel first principles calculations as such a model would be much too demanding with regard to computation time. As a first approach, we therefore neglect the interactions with the lattice and treat the clusters as free, without imposing unnatural symmetry constraints.

The results of these calculations are found in Table 2. Because we aim at detecting local minima in the vicinity of icosahedral symmetry, we used symmetric structures for the starting configurations. During the optimizations, the symmetry was broken in all cases. Symmetry breaking is a common feature of small clusters. It is caused by the Jahn-Teller effect and the magnetic alignment in the clusters. The clusters tend to have slightly asymmetric geometries with a bond length variation of about $0.1 \AA$ (see bond lengths in Table 2), but they can still be considered as icosahedral structures as can be seen in Figure 11. Considering that experiments may show some sort of dynamic average but nevertheless reveal a small anisotropy, the calculations are well compatible.

All clusters possess a nonzero magnetic moment. For most of the systems, it is between 2 and 4 Bohr magnetons $\left(\mu_{\mathrm{B}}\right)$, while the highly symmetric $\mathrm{Pt}_{13} \mathrm{H}_{12}$ and $\mathrm{Pt}_{13} \mathrm{H}_{12}{ }^{+1}$ clusters have very high moments of 8 and $7 \mu_{\mathrm{B}}$. This is a clear sign that hydrogen coverage alters the magnetic order in the clusters. It could clearly be seen also in the analysis of the spin density of the systems.

As mentioned by other authors, ${ }^{21}$ the coverage of the $\mathrm{Pt}$ cluster with hydrogen causes the cluster to expand, because hydrogen adsorption decreases the electron density between the $\mathrm{Pt}$ atoms, which leads to an increase of the $\mathrm{Pt}-\mathrm{Pt}$ bond length. The charge transfer from the platinum to the hydrogen atoms as well as the expansion of the cluster was clearly verified by our simulations. The effect is the stronger, the more hydrogen is on the surface.

Furthermore, it seems to be of a local nature, as Pt atoms which bind to hydrogen have a longer bond to the central $\mathrm{Pt}$ atom than atoms which do not bind to hydrogen on the same 
TABLE 2: DFT Results for $\mathbf{H}_{2}, \mathbf{P t}_{13}$, and $\mathbf{P t}_{13} \mathbf{H}_{m}$

\begin{tabular}{|c|c|c|c|c|c|c|c|c|}
\hline & & \multirow[b]{2}{*}{$E_{\mathrm{tot}}(\mathrm{eV})^{a}$} & \multirow[b]{2}{*}{$E_{\mathrm{des}}\left(\mathrm{H}_{2}\right)(\mathrm{eV})^{b}$} & \multirow[b]{2}{*}{$\operatorname{IP}(\mathrm{eV})^{c}$} & \multirow[b]{2}{*}{$\mu\left(\mu_{\mathrm{B}}\right)^{d}$} & \multicolumn{3}{|c|}{ bond length $(\AA)$} \\
\hline species & & & & & & $\mathrm{Pt}_{\mathrm{c}}-\mathrm{Pt}_{\mathrm{s}}^{e}$ & $\mathrm{Pt}_{\mathrm{s}}-\mathrm{Pt}_{\mathrm{s}}{ }^{e}$ & $\mathrm{Pt}_{\mathrm{s}}-\mathrm{H}^{e}$ \\
\hline & $\mathrm{H}_{2}$ & -6.724 & & 15.10 & 0 & & & \\
\hline & $\mathrm{Pt}_{13}$ & -53.954 & & 7.02 & 2 & $2.58-2.68$ & $2.74-2.84$ & \\
\hline & $\mathrm{Pt}_{13}{ }^{+1}$ & -46.936 & & & 3 & $2.58-2.69$ & $2.74-2.82$ & \\
\hline bridge & $\mathrm{Pt}_{13} \mathrm{H}_{1}+1$ & -51.049 & 1.50 & & 4 & $2.60-2.70$ & $2.65-2.89$ & 1.77 \\
\hline hole & $\mathrm{Pt}_{13} \mathrm{H}_{1}^{+1}$ & -50.834 & 1.07 & & 2 & $2.59-2.67$ & $2.72-2.85$ & $1.87,1.92$ \\
\hline top & $\mathrm{Pt}_{13} \mathrm{H}_{1}^{+1}$ & -50.870 & 1.14 & & 2 & $2.55-2.78$ & $2.69-2.86$ & 1.58 \\
\hline \multirow[t]{2}{*}{ bridge } & $\mathrm{Pt}_{13} \mathrm{H}_{30}$ & -164.436 & 0.64 & 6.87 & 2 & $2.80-2.87$ & $2.96-2.99$ & $1.79-1.82$ \\
\hline & $\mathrm{Pt}_{13} \mathrm{H}_{30}+1$ & -157.567 & 0.65 & & 3 & $2.77-2.87$ & $2.94-3.03$ & $1.75-1.85$ \\
\hline \multirow[t]{2}{*}{ hole } & $\mathrm{Pt}_{13} \mathrm{H}_{20}$ & unstable & & & & & & \\
\hline & $\mathrm{Pt}_{13} \mathrm{H}_{20}+1$ & unstable & & & & & & \\
\hline \multirow[t]{2}{*}{ top } & $\mathrm{Pt}_{13} \mathrm{H}_{12}$ & -100.153 & 0.97 & 7.84 & 8 & 2.67 & $2.80-2.82$ & 1.58 \\
\hline & $\mathrm{Pt}_{13} \mathrm{H}_{12}+1$ & -92.292 & 0.84 & & 7 & 2.67 & $2.81-2.82$ & 1.58 \\
\hline
\end{tabular}

${ }^{a} E_{\text {tot }}$ : total energy. ${ }^{b} E_{\text {des }}\left(\mathrm{H}_{2}\right)$ : desorption energy per $\mathrm{H}_{2}$ molecule. ${ }^{c} \mathrm{IP}$ : ionization potential. ${ }^{d} \mu$ : magnetic moment. ${ }^{e} \mathrm{Pt}_{\mathrm{c}}-\mathrm{Pt}_{\mathrm{s}}, \mathrm{Pt}_{\mathrm{s}}-\mathrm{Pt}_{\mathrm{s}}$, and $\mathrm{Pt}_{\mathrm{s}}-\mathrm{H}$ : bond lengths from the central Pt atom to a surface Pt atom, between two surface Pt atoms, and between a surface Pt atom and an $\mathrm{H}$ atom, respectively.

cluster. This explains why the $\mathrm{Pt}_{13} \mathrm{H}_{1}{ }^{+1}$ cluster which carries only one hydrogen atom is particularly asymmetric.

When a hydrogen atom is adsorbed to the Pt cluster, it will remain at symmetric positions in order to maximize its binding energy. For an icosahedral cluster, three sites can be considered: top, hole, and bridge (parts $\mathrm{a}-\mathrm{c}$ of Figure 11). In the first series of calculations, we checked the stability and energetics of a single $\mathrm{H}$ atom at these sites on $\mathrm{Pt}_{13}{ }^{+1}$. The bridge position is by far the most stable configuration, as it has the highest desorption energy (Table 2). The least stable is the hole site. The stability of each site was checked against perturbations by displacing the atom away from the symmetric position and relaxing the structure back to equilibrium. A hydrogen atom on the bridge position always returned to the highly symmetric equilibrium position. However, a single hydrogen atom on a top site apparently does not favor a symmetric position (Figure 11c); it seems to have several equivalent potential minima, all within a distance of $1.58 \AA$ from the nearest-neighbor Pt atom. The hole site is stable for small displacements of $0.1 \AA$, but when the bond is elongated by $0.3 \AA$, the hydrogen atom moves to a bridge site. This means that the hole site for a single $\mathrm{H}$ atom has a very shallow local potential minimum that can easily be destroyed by thermal vibrations. The only stable positions for a single hydrogen atom on a $\mathrm{Pt}_{13}{ }^{+1}$ cluster seem to be the bridge and the top sites. These results are in striking contrast to studies of hydrogen adsorption on $\mathrm{Pt}(111)$ single-crystal surfaces, ${ }^{53,54}$ where much lower $\mathrm{H}_{2}$ desorption energies of 0.86 $\mathrm{eV}$ (top), $0.80 \mathrm{eV}$ (bridge), $0.86 \mathrm{eV}$ (hole, fcc), and $0.78 \mathrm{eV}$ (hole, hexagonal close packed (hcp)) were reported and the potential differences are small, ${ }^{54}$ whereas the $\mathrm{Pt}-\mathrm{H}$ bond lengths associated with different sites agree very well within $0.01 \AA$.

For a highly symmetric $\mathrm{Pt}_{13} \mathrm{H}_{\mathrm{m}}{ }^{+1}$ cluster covered completely with hydrogen, three possible structures exist: $\mathrm{Pt}_{13} \mathrm{H}_{12}{ }^{+1}$, $\mathrm{Pt}_{13} \mathrm{H}_{20}{ }^{+1}$, and $\mathrm{Pt}_{13} \mathrm{H}_{30}{ }^{+1}$. This corresponds to the hydrogen atoms bound on top of surface Pt atoms, in the hole of the 20 surface facets, and on the 30 bridges, respectively (Figure 11). We suppose that one of these structures is that with the maximum hydrogen loading seen in the EPR experiment (Figure 8). The most striking result for this set of structures is that for complete hydrogenation the hole sites are not stable. During optimization of the $\mathrm{Pt}_{13} \mathrm{H}_{20}{ }^{+1}$ and $\mathrm{Pt}_{13} \mathrm{H}_{20}$ structures, the hydrogen moves to bridge or top sites, deforming the cluster heavily. This is a consequence of our finding that for a single hydrogen atom the hole site has only a very shallow potential minimum. For full hydrogenation, this local minimum seems to have disappeared completely. The remaining two stable structures, $\mathrm{Pt}_{13} \mathrm{H}_{12}{ }^{+1}$ and $\mathrm{Pt}_{13} \mathrm{H}_{30}{ }^{+1}$, are displayed in Figure 11 .
$\mathrm{Pt}_{13} \mathrm{H}_{12}{ }^{+1}$ is highly symmetric, has a very high magnetic moment, and the $\mathrm{Pt}-\mathrm{H}$ bond length is identical to that of $\mathrm{Pt}_{13} \mathrm{H}_{1}{ }^{+1} \cdot \mathrm{Pt}_{13} \mathrm{H}_{30}{ }^{+1}$ in turn is less symmetric, the $\mathrm{Pt}-\mathrm{H}$ bond lengths show considerable variation, and the magnetic moment is indistinguishable from that of $\mathrm{Pt}_{13}{ }^{+1}$.

In Table 2, we see that for complete hydrogenation desorption energies change significantly, as now the top site seems to be the most favorable. For Pt(111) flat surface calculations, there seems to be no significant difference between the adsorption of a single $\mathrm{H}$ atom (see above) and the adsorption of a whole hydrogen monolayer $\left(E_{\mathrm{des}}\left(\mathrm{H}_{2}\right)=0.77 \mathrm{eV}\right.$ (top), $0.71 \mathrm{eV}$ (bridge), $0.75 \mathrm{eV}$ (hole, hcp), and $0.85 \mathrm{eV}$ (hole, fcc)). ${ }^{54}$ In our case, the adsorption energy of $\mathrm{Pt}_{13} \mathrm{H}_{30}{ }^{+1}$ drops below the values of the (111) surfaces, while the $\mathrm{Pt}_{13} \mathrm{H}_{12}{ }^{+1}$ is just as good as these systems. This different behavior is attributed to a finite size effect due to the limited number of electrons in a cluster. As already mentioned, the binding of hydrogen to the surface causes a partial electron transfer from the cluster to the hydrogen. For a single hydrogen atom, there are enough electrons available to achieve an optimum bonding. But, when the surface is covered by more and more hydrogen atoms, the number of electrons that are available in a cluster is more and more limited, the bonds become weaker (i.e., the bond lengths increase), and the binding energy decreases. This can indeed be seen from the fact that for the $\mathrm{Pt}_{13} \mathrm{H}_{30}{ }^{+1}$ system the average $\mathrm{Pt}-\mathrm{H}$ bond length is larger than that for the $\mathrm{Pt}_{13} \mathrm{H}_{1}{ }^{+1}$ (bridge) case and the binding energy is more than $50 \%$ smaller. For the top sites, a single bond has a lower binding energy and we conjecture that also the electron transfer is smaller. So for coverage with only $12 \mathrm{H}$ atoms, the binding energy per $\mathrm{H}_{2}$ is only $30 \%$ smaller than that for $\mathrm{Pt}_{13} \mathrm{H}_{1}{ }^{+1}$ (top) and the $\mathrm{Pt}-\mathrm{H}$ bond length is the same. Overall, hydrogen molecules adsorbed on all symmetric top positions can gain more binding energy than the ones adsorbed on the bridge sites. For hydrogen adsorbed on a bulk metal surface in turn, the metallic support is a large electron reservoir and it makes nearly no difference whether a single atom or an entire monolayer is adsorbed.

\section{Discussion}

4.1. Characterization of the Cluster. Deuterium is favored over hydrogen in the formation of the cluster, which results in the deuterated sample always giving a stronger EPR spectrum than the hydrogen-reduced sample by a factor of 2.8. This factor should be unity if there is a given number of clusters in the sample that can be exchanged, and it must mean that the clusters are in equilibrium with an EPR invisible reservoir of similar 
TABLE 3: Calculated Energies for Hydrogenated Pt Clusters with Different Spin States $S(0 \leq S \leq 5)$

\begin{tabular}{|c|c|c|c|c|c|c|c|c|c|c|c|}
\hline \multirow[b]{2}{*}{ system } & \multicolumn{11}{|c|}{ energy of different spin states } \\
\hline & 0 & $1 / 2$ & 1 & $3 / 2$ & 2 & $5 / 2$ & 3 & $7 / 2$ & 4 & $9 / 2$ & 5 \\
\hline $\begin{array}{l}\mathrm{Pt}_{13} \mathrm{H}_{1}^{+1} \text { (bridge) } \\
\mathrm{Pt}_{13} \mathrm{H}_{1}^{+1} \text { (hole) } \\
\mathrm{Pt}_{13} \mathrm{H}_{1}^{+1} \text { (top) } \\
\mathrm{Pt}_{13} \mathrm{H}_{30} \text { (bridge) }\end{array}$ & $\begin{array}{l}+3.51^{b} \\
+15.99^{b} \\
+10.38^{b}\end{array}$ & & $\begin{array}{l}+1.27^{b} \\
-50.8342^{a} \\
-50.870^{a} \\
-164.44^{a}\end{array}$ & & $\begin{array}{l}-51.0487^{a} \\
+2.52^{b} \\
+14.21^{b} \\
+53.72^{b}\end{array}$ & & $+1.92^{b}$ & & & & \\
\hline $\begin{array}{l}\mathrm{Pt}_{13} \mathrm{H}_{30}{ }^{+1} \text { (bridge) } \\
\mathrm{Pt}_{13} \mathrm{H}_{12} \text { (top) } \\
\mathrm{Pt}_{13} \mathrm{H}_{12}{ }^{+1} \text { (top) }\end{array}$ & & $+2.25^{b}$ & $+70.19^{b}$ & $-157.57^{a}$ & $+51.98^{b}$ & $\begin{array}{l}+65.59^{b} \\
+21.82^{b}\end{array}$ & $+33.30^{b}$ & $-92.292^{a}$ & $-100.15^{a}$ & $+38.70^{b}$ & $+128.12^{b}$ \\
\hline
\end{tabular}

${ }^{a}$ Ground-state energy in electronvolts. ${ }^{b}$ Energy offset of excited state in $\mathrm{kJ} \mathrm{mol}^{-1}$.

clusters and that hydrogen-deuterium exchange is able to shift this equilibrium due to zero-point energies.

It would be interesting to compare the observed $\mathrm{Pt}$ and $\mathrm{H}$ hyperfine couplings as well as the $g$ values with theoretical calculations. Even though very significant progress has been made over the past decade in this field, clusters containing several heavy atoms such as Pt seem to be somewhat out of reach at this point, especially for spin density calculations.

The HYSCORE experiment in Figure 5 revealed anisotropic proton hyperfine tensors. The anisotropic part of the hyperfine interaction was calculated from the displacement of the HY$\mathrm{SCORE}$ ridges. According to the point-dipole approximation, $\Delta v_{\mathrm{s}} \approx 0.16 \mathrm{MHz}$ yields $T \approx 2.63 \mathrm{MHz}$, from which a distance of about $3.3 \AA$ between the electron spin and the hydrogen nuclei is obtained. Considering that due to the $r^{-3}$ dependence the delocalized electron spin from the remote side of the Pt cluster contributes much less than the fraction close to a given proton, this is a very reasonable number.

The previous HYSCORE experiment revealed that the $\mathrm{Pt}$ cluster in $\mathrm{KL}$ is also coupled with $\mathrm{Al}$ and $\mathrm{Si}$ nuclei, which means that there is a dipolar or contact interaction between the $\mathrm{Pt}$ cluster and the zeolite framework. ${ }^{43}$ As we know, the Pt-D bond is slightly shorter than that of $\mathrm{Pt}-\mathrm{H}$, so the $\mathrm{D}_{2}$-reduced or exchanged cluster has a slightly smaller size than the $\mathrm{H}_{2-}$ reduced or exchanged cluster. It is therefore conceivable that the smaller Pt cluster will interact less and is less distorted by the zeolite framework. Therefore, the deuterated cluster leads to a more symmetrical EPR spectrum (see Figure 3).

It is always an interesting question regarding how many metal atoms one needs to make a cluster metallic, and there are various ways to look at this point. ${ }^{55}$ In metals, the spin-lattice relaxation proceeds via the contact interaction between the nuclear spins and the spins of conduction electrons. The nuclear spin-lattice relaxation time $T_{1}$ of metals is known to vary inversely with the absolute temperature $T$ (Korringa relation). ${ }^{56}$ The present system shows a two-component relaxation, and both relaxation times $\tau_{1}$ and $\tau_{2}$ scale as $T^{-2}$ (Figure $6 \mathrm{~b}$ ), which means that the Pt cluster does not follow the Korringa relation and is nonmetallic. It should be regarded as a molecule and not as a metallic cluster. The same conclusion is derived from the fact that the EPR spectrum consists of a discrete multiplet. Scattering of the conduction electron of a metal would flip the nuclear spins and wash out any hyperfine structure, leading to a single line that is well-known from conduction electron EPR. A $T^{2}$ dependence is normally ascribed to a two-phonon Raman-type relaxation process due to inelastic scattering of phonons by spins. ${ }^{52}$ Alternatively, one of the components could be due to spin diffusion in a suitable environment.

A ground-state system in a given environment is normally expected to exhibit a single relaxation rate. The presence of two clearly distinguishable relaxation components indicates that the cluster is found in two different environments. This may be due to paramagnetic centers in the environment, such as iron (see Figure 1) or more likely, since Fe is present as an impurity at a ppm level only, as Pt in the form of high-spin cluster species that are EPR silent at X-band frequencies.

As long as the Pt cluster is covered by hydrogen, each chemisorbed $\mathrm{H}$ atom pins in its chemical bond one of the $\mathrm{d}$ electrons of Pt. Upon desorption, the pinned d electrons are released and the EPR signal is lost, possibly leaving an extremely broad line that gives rise to an observed baseline shift that is unfortunately not reliably distinguished from a broad line profile (Figure 8). According to Kawabata's theory, very small metallic particles should indeed lead to very broad EPR lines. ${ }^{57}$ This would be compatible with our observation and might mean that upon hydrogen desorption the cluster transforms from a molecular to a metallic species. A metallic nature has been ascribed to nickel clusters with as few as 3-7 atoms based on their continuous UV absorption spectra. ${ }^{58}$ In any case, the fact that the EPR signal is recovered upon readsorption of hydrogen must mean that the cluster keeps its stoichiometric identity and does not disintegrate or agglomerate upon desorption.

We have no reliable experimental clue about the charge or the electron spin state of the cluster. During ion exchange, $\mathrm{Pt}^{2+}$ replaces $\mathrm{Na}^{+}$as balancing charges for the negatively charged zeolite lattice. During hydrogen reduction and cluster formation, $\mathrm{Pt}$ is partly or fully reduced and the protons take the role of the charge balancing ions. Each neutral Pt atom contributes an even number of electrons. Any neutral Pt cluster will therefore have a diamagnetic or integer-spin paramagnetic ground state. Chemisorption of $\mathrm{H}_{2}$ molecules does not change this situation. Integer-spin systems are often EPR silent at X-band frequencies, and when observed, they should be accompanied by a halffield $\left(\Delta m_{\mathrm{s}}=2\right)$ and possibly by higher-order transitions. There is no evidence of such a transition; we therefore assume that the observed cluster signal belongs most likely to a $S=1 / 2$ system, which would imply an odd charge. The 12-ring window of a faujasite supercage in the average contains three negative charges due to aluminum atoms which can balance a single or perhaps triple positive charge of a Pt cluster that sits in this ring. Consultation of Table 3 reveals that, while all ground states of the calculated species are predicted to be $S>1 / 2, \mathrm{Pt}_{13} \mathrm{H}_{30}{ }^{+1}$ has a $S=1 / 2$ state that is only $2.25 \mathrm{~kJ} \mathrm{~mol}^{-1}$ above the ground state. When the accuracy of the calculation which treats the cluster as free and neglects its interaction with the zeolite is taken into account, it is conceivable that the energetic order is reversed. In fact, the calculations predict low-lying excited states for several species, so that an interesting temperature dependence of magnetization may be expected (vide infra).

The observed cluster must be particularly stable. It is wellknown that cluster sizes matching a magic number are often much more stable than others. $\mathrm{Pt}_{13}$ is one of the smallest magic clusters, and for icosahedral symmetry, it has 12 equivalent $\mathrm{Pt}$ atoms surrounding another atom in the center. Despite the fact that only 12 equivalent nuclei were detected by EPR, the observed cluster is suggested to be icosahedral $\mathrm{Pt}_{13}$, with no 
significant spin density populating the 13th atom in the center so that it is invisible.

Pt nanoparticles with an average diameter of $1 \mathrm{~nm}$ were also reported by Weckhuysen et al. ${ }^{15}$ Since they were prepared on $\mathrm{NaY}$ by a similar procedure and characterized by high-resolution transmission electron microscopy (HRTEM) and extended X-ray absorption fine structure (EXAFS), this supports the present observations and implies that the EPR silent clusters are of approximately the same size.

Our theoretical calculations suggest that the $\mathrm{Pt}-\mathrm{Pt}$ bond length is about $7-8 \%$ shorter for the naked $\mathrm{Pt}_{13}$ cluster than for the fully hydrogen-covered $\mathrm{Pt}_{13} \mathrm{H}_{30}$ cluster. This is consistent with the reported EXAFS experimental results by Koningsberger et al. ${ }^{21 \mathrm{a}}$ The adsorbed hydrogen alters the electronic properties of the Pt atoms, decreasing the electron density between the atoms, which in turn leads to the increase of the $\mathrm{Pt}-\mathrm{Pt}$ bond length.

4.2. Hydrogen Desorption Mechanism. Perhaps the most interesting and intriguing point to be commented on is how the EPR signal disappears when hydrogen is desorbed. It is clear from Figure 8 that a partially desorbed sample has the same splitting pattern as the initial sample, thus it can simply be scaled and superimposed with the initial spectrum, with only a subtle difference that remains to be discussed further below in context with Figure 9a. Most remarkably, the Pt atoms remain equivalent during desorption. Intuitively, we would have expected that $\mathrm{Pt}$ atoms bound to $\mathrm{H}$ are distinguishable from those which are not in direct contact with $\mathrm{H}$. There is a number of ways which may be considered to explain this behavior: (i) The hydrogen atoms are mobile on the surface and remain so down to a temperature of $4 \mathrm{~K}$ so that all $\mathrm{Pt}$ atoms see the same average $\mathrm{H}$ population. Dynamics down to such low temperature may be surprising; furthermore, one might expect that the spin density at the $\mathrm{Pt}$ nuclei and thus the hyperfine splitting would shift progressively during desorption, which is not the case. (ii) The cluster becomes EPR silent when the first or the first few $\mathrm{H}_{2}$ molecules desorb. This may be because it becomes metallic (iia), diamagnetic (iib), or it switches to an EPR silent high-spin state (iic). While we have not been able to prove that the observable signal corresponds to a doublet (single unpaired electron spin) state, we have no indication that it is not. Such a state would become diamagnetic when it acquires or loses an electron to some other center in the environment. We do have evidence from further experiments to be reported elsewhere that the cluster can be oxidized. However, upon hydrogen desorption there is no other state that comes up when the cluster signal goes away. The conversion of high-spin states is quite an attractive option since the predicted numbers (Table 3 ) for the lowest spin states of $\mathrm{Pt}_{13} \mathrm{H}_{30}{ }^{+1}$ are within a few $\mathrm{kJ} \mathrm{mol}^{-1}$ (the sequence may be reversed in reality), and it is not unreasonable that a slight change in surface coverage affects the energetics considerably.

It is interesting that the hyperfine anisotropy is of oblate axial symmetry $\left(A_{\|}<A_{\perp}\right)$ after $\mathrm{D}_{2}$ reduction or exchange but changes to prolate axial symmetry $\left(A_{\|}>A_{\perp}\right)$ after partial $\mathrm{D}_{2}$ desorption at $343 \mathrm{~K}$ for about $60 \mathrm{~min}$ (see Figure 9a and Table 1), an effect that is not so large but fully reproducible. First of all, this means either that the EPR signal does not disappear upon desorption of the first hydrogen molecule as conjectured above or that the clusters reside in different environments with slightly different EPR parameters and that hydrogen desorbs more easily from one of these environments than from the other one. The effect is a reminder of several reports in the literature that two different kinds of hydrogen are present on a platinum surface, one which is more strongly and the other which is more weakly chemisorbed. ${ }^{21 \mathrm{a}, 25}$ The two types of surface hydrogen do not show up as double exponentials in the desorption curves (Figure 10a).

4.3. Hydrogen Desorption Energy. A perhaps better explanation than the different cluster environments which are hard to justify in the highly symmetric faujasite structure is suggested based on the results of the quantum chemical calculations (Table 2). These show convincingly that $30 \mathrm{H}$ atoms can be chemisorbed on the bridge sites of $\mathrm{Pt}_{13}$. Upon desorption, when the coverage is down to 12 atoms, the calculation predicts that these remaining atoms are more stable when bound on top of Pt. It is plausible that this change in bonding is accompanied by a change in the Pt hyperfine tensor. It is conceivable but has not been checked experimentally that it would also affect the $\mathrm{H}$ hyperfine tensor.

The molecular hydrogen desorption energy of $1.36 \mathrm{eV}$ (131 $\mathrm{kJ} \mathrm{mol}^{-1}$ ) that was determined from the desorption experiments from the cluster (Figure 10) is clearly higher than the corresponding experimental values for desorption from a (111) singlecrystal surface which centers around $0.8 \mathrm{eV} .{ }^{54}$ The difference reveals a clear finite size effect. The coordination number of surface Pt atoms on the cluster is 6, which is less than that of a $\operatorname{Pt}(111)$ crystal surface, where it is 9. Atoms with a low coordination number have in general a higher desire to saturate their coordination sphere and form stronger bonds, which is also the origin of the different catalytic activity of corner, edge, and kink atoms of catalyst particles. It should furthermore be noted that the experimental desorption energy corresponds to the hydrogen coverage at which the EPR signal is lost. In view of the above discussion, this may be for less or about $12 \mathrm{H}$ atoms per cluster. The desorption energy from the theoretical calculation is in reasonable agreement with the experimental value.

It is interesting also that comparable DFT calculations for a $\operatorname{Pt}(111)$ crystal surface predict that the top site for a single hydrogen atom represents a local energy minimum that is only slightly higher than the fcc 3 -fold hole site. This is different for the icosahedral $\mathrm{Pt}_{13}$ cluster where the bridged site is the most stable one (see Table 2), about $0.22 \mathrm{eV}$ lower for $\mathrm{Pt}_{13} \mathrm{H}_{1 \text {,bridge }}{ }^{+1}$ (one $\mathrm{H}$ atom on the bridge site) than for $\mathrm{Pt}_{13} \mathrm{H}_{1 \text {,hole }}{ }^{+1}$ (one $\mathrm{H}$ atom on the hole site), which means that one $\mathrm{H}$ atom adsorption on the icosahedral $\mathrm{Pt}_{13}$ bridge site is slightly more stable than on top and hole sites.

There is an important practical implication of the different binding sites of $\mathrm{H}$ on the surface of platinum. Hydrogen chemisorption is often used to determine the dispersion of $\mathrm{Pt}$ catalysts. This is done on the basis that there is one $\mathrm{H}$ atom per surface $\mathrm{Pt}$ atom, that is, it rests on the assumption that $\mathrm{H}$ binds atop Pt. We learn here that a factor of 2.5 more hydrogen can be accommodated by binding at the bridge sites of a 13-atom cluster. For a (111) single-crystal Pt surface, there is still a factor of 1.5 more bridge sites than surface atoms. This may mean that the dispersion of Pt catalysts based on hydrogen chemisorption is often overestimated.

4.4. Cluster Magnetization. The temperature dependence of magnetization shows marked non-Curie behavior. Since the magnetization of field cooling and zero-field cooling is the same (see Figure 7), a freezing of magnetism at low temperature can be excluded. From $30 \mathrm{~K}$ to about $50 \mathrm{~K}$, the Pt clusters obey approximately Curie paramagnetic behavior. Assuming that the clusters are $S=1 / 2$, we calibrate the number of spins against our standard and obtain $n=3.9 \times 10^{15} \mathrm{spins} \cdot \mathrm{g}^{-1}$, and on the basis that there is 1 unpaired electron per $13 \mathrm{Pt}$ atoms, we conclude that only $0.03 \%$ of the total number of $\mathrm{Pt}$ atoms in the sample contribute to the EPR cluster signal at this temper- 
ature. This is much less than what was found in earlier work for $\mathrm{Pt} / \mathrm{KL},{ }^{43}$ which could point to an interesting electronic influence of the zeolite structure and composition ( $\mathrm{K}$ in place of $\mathrm{Na}$ ) on the fraction of high spin or other EPR invisible states. Ongoing superconducting quantum interference device (SQUID) magnetization and XAFS measurements are expected to clarify the nature of this fraction of Pt.

In the high-temperature range, the signal disappears faster than according to Curie. Neither the splitting pattern nor the line widths of the EPR spectrum change with increasing temperature. This means that there is no other EPR active state that starts to contribute. What must be happening is that the cluster is transformed to a diamagnetic or an EPR silent paramagnetic (high-spin) state. This is the third piece of evidence that some invisible reservoir with reversible access is involved with a nature that is difficult to specify based on the present data. According to the above calibration, it may involve up to 99.97\% of the total Pt loading in $\mathrm{Pt} / \mathrm{NaY}$.

The sharp change in the EPR amplitude of the cluster signal near $17 \mathrm{~K}$ is untypical and remains somewhat mysterious after several tests (see section 3.1).

\section{Concluding Remarks}

Chemisorbed hydrogen on Pt catalysts is of great technical importance, yet it is somewhat elusive and has been the subject of many discussions and speculations. Here, we have demonstrated that EPR can be used to study $\mathrm{H}$ adsorption to and desorption from a paramagnetic icosahedral $\mathrm{Pt}_{13} \mathrm{H}_{m}$ ( $m$ up to 30) nanocluster which is stabilized in a zeolite. The results give evidence of a finite size effect and have interesting implications for the mechanism of desorption as well as on magnetic properties. Despite the fact that only a small fraction of the deposited Pt is observed, the signal provides direct access to study catalytic processes on a well-defined catalytic center. Such work is under way and will be reported in due course.

Acknowledgment. We gratefully acknowledge the help from A. Panchenko and Ch. Remenyi for valuable discussions and an introduction to DFT calculations, as well as CU Chemie Uetikon AG in Switzerland for providing the zeolites. X.L. thanks the International Max Planck Research School for Advanced Materials (IMPRS-AM) for scholarship support.

\section{References and Notes}

(1) Halperin, W. P. Rev. Mod. Phys. 1986, 58, 533.

(2) Gates, B. C. Chem. Rev. 1995, 95, 511.

(3) Toshima, N.; Yonezawa, T. New J. Chem. 1998, 11, 1179.

(4) Kreibig, U.; Vollmer, M. Optical Properties of Metal Clusters; Springer Series in Materials Science; Springer: Berlin, Germany, 1995; Vol. 25.

(5) de Heer, W. A. Rev. Mod. Phys. 1993, 65, 611.

(6) (a) Li, J.; Li, X.; Zhai, H. J.; Wang, L. S. Science 2003, 299, 864. (b) Johansson, M. P.; Sundholm, D.; Vaara, J. Angew. Chem. 2004, 116, 2732. (c) Sun, S.; Murray, C. B.; Weller, D.; Folks, L.; Moser, A. Science 2000, 287, 1989. (d) Majetich, S. A.; Jin, Y. Science 1999, 284, 470.

(7) Santra, A. K.; Goodman, D. W. J. Phys.: Condens. Matter. 2002, 14, R31.

(8) Heiz, U.; Bullock, E. L. J. Mater. Chem. 2004, 14, 564.

(9) Larsen, G.; Haller, G. L. Catal. Lett. 1989, 3, 103.

(10) Sachtler, W. H. M. Catal. Today 1992, 15, 419.

(11) Mojet, B. L.; Kappers, M. J.; Miller, J. T.; Koningsberger, D. C. Stud. Surf. Sci. Catal. 1996, 101, 1165.

(12) Vaarkamp, M.; Miller, J. T.; Modica, F. S.; Koningsberger, D. C. J. Catal. 1996, 163, 294.

(13) Heiz, U.; Sanchez, A.; Abbet, S.; Schneider, W.-D. J. Am. Chem. Soc. 1999, 121, 3214
(14) de Graaf, J.; van Dillen, A. J.; de Jong, K. P.; Koningsberger, D. C. J. Catal. 2001, 203, 307.

(15) Visser, T.; Nijhuis, T. A.; van der Eerden, A.; Jenken, K.; Ji, Y.; Bras, W.; Nikitenko, S.; Ikeda, Y.; Lepage, M.; Weckhuysen, B. M. J. Phys. Chem. B 2005, 109, 3822.

(16) Kaldor, A.; Cox, D. M. J. Chem. Soc., Faraday Trans. 1990, 86, 2459.

(17) Geusic, M. E.; Morse, M. D.; Smalley, R. E. J. Chem. Phys. 1985, 82,590 .

(18) Cui, Q.; Musaev, D. G.; Morokuma, K. J. Chem. Phys. 1998, 108 , 8418.

(19) Buckart, S.; Ganteför, G.; Kim, Y. D.; Jena, P. J. Am. Chem. Soc. 2003, 125, 14205.

(20) Andersson, M.; Rosen, A. J. Chem. Phys. 2002, 117, 7051

(21) (a) Oudenhuijzen, M. K.; Bitter, J. H.; Koningsberger, D. C. J. Phys. Chem. B 2001, 105, 4616. (b) Oudenhuijzen, M. K.; van Bokhoven J. A.; Ramaker, D. E.; Koningsberger, D. C. J. Phys. Chem. B 2004, 108, 20247. (c) Oudenhuijzen, M. K.; van Bokhoven J. A.; Miller, J. T.; Ramaker, D. E.; Koningsberger, D. C. J. Am. Chem. Soc. 2005, 127, 1530. (d) Ramaker, D. E.; Dorssen, G. E.; Mojet, B. L.; Koningsberger, D. C. Top. Catal. 2000, 10, 157. (e) Miller, J. T.; Meyers, B. L.; Modica, F. S.; Lane, G. S.; Vaarkamp, M.; Koningsberger, D. C. J. Catal. 1993, 143, 395. (f) Miller, J. T.; Meyers, B. L.; Barr, M. K.; Modica, F. S.; Koningsberger, D. C. J. Catal. 1996, 159, 41 .

(22) Doyle, A. M.; Shaikhutdinov, S. K.; Jackson, S. D.; Freund, H. J. Angew. Chem., Int. Ed. 2003, 42, 5240.

(23) Buckart, S.; Ganteför, G.; Kim, Y. D.; Jena, P. J. Am. Chem. Soc. 2003, 125, 14205

(24) Tong, Y. Y.; Klink, J. J. J. Phys. Chem. 1994, 98, 11011.

(25) (a) Chesters, M. A.; Dolan, A.; Lenon, D.; Williamson, D. J. J. Chem. Soc., Faraday Trans. 1990, 86, 3491. (b) Chesters, M. A.; Packer, K. J.; Viner, H. E. Wright, M. A. J. Chem. Soc., Faraday Trans. 1995, 91 , 2203. (d) Chesters, M. A.; Packer, K. J.; Viner, H. E.; Wright, M. A.; Lennon, D. J. Chem. Soc., Faraday Trans. 1996, 92, 4709.

(26) Koningsberger, D. C.; Oudenhuijzen, M. K.; Bitter, J. H.; Ramaker, D. E. Top. Catal. 2000, 10, 167.

(27) Bergeret, G.; Gallezot, P. Particle Size and Dispersion Measurements. In Handbook of Heterogeneous Catalysis; Ertl, G., Knözinger, H., Weitkamp, J., Eds.; VCH: Weinheim, Germany, 1997; Vol. 2, pp 445446.

(28) Hori, H.; Yamamoto, Y.; Iwamoto, T.; Miura, T.; Teranishi; T.; Miyake, M. Phys. Rev. B 2004, 69, 174411.

(29) Kumar, V.; Kawazoe, Y. Phys. Rev. B 2002, 66, 144413.

(30) Ganteför, G.; Eberhardt, W. Phys. Rev. Lett. 1996, 76, 4975.

(31) Moseler, M.; Häkkinen, H.; Barnett, R. N.; Landman, U. Phys. Rev. Lett. 2001, 86, 2545.

(32) Apsel, S. E.; Emmert, J. W.; Deng, J.; Bloomfield, L. A. Phys. Rev. Lett. 1996, 76, 1441.

(33) Sanchez, R. D.; Lopez-Quintela, M. A.; Rivas, J.; Gonzalez-Penedo, A.; Garcia-Bastida, A. J.; Ramos, C. A.; Zysler, R. D.; Ribeiro Guevara, S. J. Phys.: Condens. Matter. 1999, 11, 5643.

(34) Shinohara, T.; Sato, T. Phys. Rev. Lett. 2003, 91, 197201.

(35) Yamamoto, Y.; Miura, T.; Nakae, Y.; Teranishi, T.; Miyake, M.; Hori, H. Physica B 2003, 329-333, 1183.

(36) Teo, B. K.; Sloane, N. J. A. Inorg. Chem. 1985, 24, 4545.

(37) Sachtler, W. H. M. Catal. Today 1992, 15, 419.

(38) Tzou, M. S.; Teo, B. K.; Sachtler, W. H. M. J. Catal. 1988, 113, 220.

(39) Ciccariello, S.; Benedetti, A.; Pinna, F.; Strukul, G.; Jusczyk, W.; Brumberger, H. Phys. Chem. 1999, $1,367$.

(40) Xu, B.; Chen, X.; Kevan, L. J. Chem. Soc., Faraday Trans. 1991 $87,3157$.

(41) Michalik, J.; Kevan, L. J. Am. Chem. Soc. 1986, 108, 4247.

(42) Michalik, J.; Brown, D.; Yu, J. S.; Danilczuk, M.; Kim, J. Y.; Kevan, L. Phys. Chem. Chem. Phys. 2001, 3, 1705.

(43) Kevan, L. Electron Spin Reson. 1991, 99, 12B.

(44) Schmauke, T.; Eichel, R. A.; Schweiger, A.; Roduner, E. Phys. Chem. Chem. Phys. 2003, 5, 3076.

(45) (a) Kresse, G.; Hafner, J. Phys. Rev. B 1993, 47, 558. (b) Kresse, G.; Hafner, J. Phys. Rev. B 1994, 49, 14251. (c) Kresse, G.; Furthmüller, J. Comput. Mater. Sci. 1996, 6, 15

(46) (a) Blöchl, P. E. Phys. Rev. B 1994, 50, 17953. (b) Kresse, G. Joubert, J. Phys. Rev. B 1999, 59, 1758.

(47) Perdew, P. J.; Chevary, J. A.; Vosko, S. H.; Jackson, K. A.; Pederson, M. R.; Singh, D. J.; Fiolhais, C. Phys. Rev. B 1992, 46, 6671. (48) Markov, G.; Payne, M. C. Phys Rev. B 1995, 51, 4014.

(49) Goldfarb, D.; Bernardo, M.; Strohmaier, K. G.; Vaughan, D. E.

W.; Thomann, H. J. Am. Chem. Soc. 1994, 116, 6344.

(50) Dyrek, K.; Che, M. Chem. Rev. 1997, 97, 305.

(51) Pöppl, A.; Kevan, L. J. Phys. Chem. 1996, 100, 3387.

(52) Kubicki, J. D.; Apitz, S. E. Am. Mineral. 1998, 83, 1054

(53) Bowman, M. K.; Kevan, L. In Time Domain Electron Spin Resonance; Wiley: New York, 1979; Chapter 3, p 80. 
(54) Badescu, S. C.; Salo, P.; Ala-Nissila, T.; Ying, S. C.; Jacobi, K.; Wang, Y.; Bedürftig, K.; Ertl, G. Phys. Rev. Lett. 2002, 88, 136101.

(55) Papoian, G.; Nørskov, J. K.; Hoffmann, R. J. Am. Chem. Soc. 2000, 122, 4129. (55) Edwards, P. P.; Johnston, R. L.; Rao, C. N. R. On the size-Induced Metal-Insulator Transition in Clusters and Small Particles.
In Metal Clusters in Chemistry; Braunstein, P., Oro, L. A., Raithby, P. R., Eds.; Wiley: Weinheim, Germany, 1999; Vol. 3.

(56) Korringa, J. Physica 1950, 16, 601.

(57) Kawabata, A. J. Phys. Soc. Jpn. 1970, 29, 902

(58) Knickelbein, M. B. J. Chem. Phys. 1993, 99, 2377. 